\title{
CRESCIMENTO DE MOGNO-BRASILEIRO E RESISTÊNCIA A Hypsipyla grandella EM FUNÇÃO DO CÁLCIO E DO BORO ${ }^{1}$
}

Mário Lopes da Silva Junior ${ }^{2}$, João Cardoso de Souza Junior ${ }^{3}$, Ana Carolina Maciel Braga ${ }^{3}$, Orlando Shigueo Ohashi, Vânia Silva de Melo ${ }^{4}$, George Rodrigues da Silva ${ }^{5}$, Augusto José Silva Pedroso ${ }^{6}$, Ismael Jesus de Matos Viégas ${ }^{7}$ e Eduardo Cézar Medeiros Saldanha ${ }^{5}$

\begin{abstract}
RESUMO - O mogno-brasileiro possui alto valor madeireiro, mas seu cultivo comercial é inviabilizado pelo ataque da broca Hypsipyla grandella. Objetivou-se avaliar o efeito de doses de cálcio e boro nas variáveis de crescimento do mogno e na resistência ao ataque da broca $H$. grandella. O delineamento utilizado foi o fatorial $4^{2}$ em blocos ao acaso com quatro doses de cálcio $\left(0,100,200\right.$ e $\left.400 \mathrm{mg} \mathrm{L}^{-1}\right)$ e quatro de boro $\left(0 ; 0,5 ; 2 ; \mathrm{e}^{\left.\mathrm{mg} \mathrm{L}^{-1}\right)}\right.$ e três repetições com três plantas por repetição. Avaliaram-se: altura, diâmetro, massa seca aérea e de raiz, relação parte aérea:raiz, taxa de infestação e comprimento da galeria construída pela broca. Os dados foram submetidos ao teste de Tukey a 5\% e à análise de correlação e regressão. Não houve interação estatística entre os nutrientes, nem significância de altura e diâmetro do coleto. A massa de raízes e da parte aérea apresentou os maiores resultados na omissão dos elementos, verificando as menores relações parte aérea:raiz nas doses de $100 \mathrm{mg} \mathrm{L}^{-1} \mathrm{em}$ função do cálcio e $0,5 \mathrm{mg} \mathrm{L}^{-1} \mathrm{em}$ função do boro. A dose de $100 \mathrm{mg} \mathrm{Ca} \mathrm{L}^{-1}$ proporcionou a menor taxa de infestação de H. grandella. Para a resistência do mogno ao desenvolvimento da galeria, tanto o cálcio quanto o boro apresentaram significância, sendo os menores comprimentos verificados nas doses de $100 \mathrm{mg} \mathrm{L}^{-1} \mathrm{Ca}$ e $0,5 \mathrm{mg} \mathrm{L}^{-1} \mathrm{~B}$, respectivamente. Esses nutrientes influenciam a resistência do mogno ao ataque da broca e evidenciam a necessidade de estudos em condições de campo.
\end{abstract}

Palavras-chave: Swietenia macrophylla; Broca do mogno; Nutrição mineral do mogno.

\section{BRAZILIAN MAHOGANY GROWTH AND RESISTANCE TO Hypsipyla grandella UNDER CALCIUM AND BORON}

\begin{abstract}
The Brazilian mahogany has high timber value but its commercial cultivation is rendered impossible by the attack of Hypsipyla grandella shoot-borer. The aim of this study was to evaluate the effect of doses of calcium and boron on mahogany growth variables and on the resistance to the attack of its shootborer, $H$. grandella. The design was a $4^{2}$ factorial randomized blocks with four doses of calcium $(0,100$, 200 and $\left.400 \mathrm{mg} \mathrm{L}^{-1}\right)$, four doses of boron $\left(0,0.5,2\right.$ and $\left.4 \mathrm{mg} \mathrm{L}^{-1}\right)$ and three replications with three plants per replication. It was evaluated: height; diameter; air dry mass and root dry mass; relation air:root; infestation rate and length of the gallery promoted by the shoot-borer. The results were analyzed by Tukey test at 5\% and subjected to correlation analysis and regression. There was no statistical interaction between the nutrients and no significance for height and stem diameter. The mass of roots and aerial parts showed the highest results in the deletion of elements and showing the lower ratios of air: root parts in the doses of $100 \mathrm{mg}$

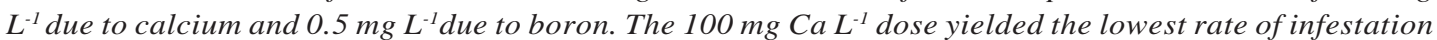
of $\mathrm{H}$. grandella. As for the resistance to the development of the mahogany gallery, both calcium and boron
\end{abstract}

\footnotetext{
${ }^{1}$ Recebido em 15.05.2013 aceito para publicação em 17.09.2014.

${ }^{2}$ Departamento de Solos, Universidade Federal Rural da Amazônia, UFRA, Belem, PA - Brasil. E-mail: <mario.silva@ufra.edu.br>. ${ }^{3}$ Graduando em Agronomia, Universidade Federal Rural da Amazônia, UFRA, Belem, PA - Brasil. E-mail: <joaocsj@gmail.com> e $<$ ana carolina_maciel@yahoo.com.br>.

${ }^{4}$ Instituto de Ciências Agrárias, Universidade Federal Rural da Amazônia, Belem, PA-Brasil. E-mail: <orlando.ohashi@ufra.edu.br> e $<$ vania.melo@ufra.edu.br $>$.

${ }^{5}$ Universidade Federal Rural da Amazônia, Departamento de Solos, UFRA, Brasil. E-mail: <george.silva@ufra.edu.br>e <eduardo.saldanha@ufra.edu.br>.

${ }^{6}$ Programa de Pós-graduação em agronomia, Universidade Federal Rural da Amazônia, Campus Paragominas, Belem, PA Brasil.E-mail: <augusto.pedroso@ufra.edu.br>.

${ }^{7}$ Empresa Brasileira de Pesquisa Agropecuária, EMBRAPA, Belem, PA - Brasil.. E-mail: <ismael@cpatu.embrapa.br>.
} 
were significant, and the smaller lengths observed at doses of $100 \mathrm{mg} \mathrm{L}^{-1}$ Ca and $0.5 \mathrm{mg} \mathrm{L}^{-1} \mathrm{~B}$, respectively. These nutrients influence the resistance of mahogany to the shoot-borer and show the need for studies in field conditions.

Keywords: Swietenia macrophylla; Mahogany shoot-borer; Mineral nutrition of mahogany.

\section{INTRODUÇÃO}

O mogno-brasileiro (Swietenia macrophylla King) é uma planta heliófila que atinge alturas de até $70 \mathrm{~m}$ e 3,5 m de diâmetro à altura do peito (CARVALHO, 2007). Há interesse de manejá-la em decorrência de seu elevado valor no mercado madeireiro (GROGAN et al., 2002; SILVA et al., 2013), fato que estimula a inclusão da espécie em programas de reflorestamento e sistemas agroflorestais (VIEIRA, 2007). O estímulo à sua exploração ilegal ocorre, principalmente, pela grande aceitação no mercado devido ao fato de a sua madeira possuir elevada qualidade. No mercado abastecido com madeiras ilegais, o mogno possui significativa parcela. Segundo estimativas, $50 \%$ das exportações de madeira da Amazônia, África Central, Sudeste da Ásia e da Rússia são provenientes de extrações ilegais (DEGEN et al., 2013).

O mogno-brasileiro ocorre em circunstâncias naturais, a exemplo das florestas nativas do Pará - Amazônia oriental - e não se verificam limitações no seu crescimento quando em função da fertilidade do solo (NORGHAUER et al., 2008); entretanto, esse fato foi observado quando as florestas foram plantadas em larga escala (OHASHI et al., 2008). Ohashi et al. (2002) e Wallau et al. (2008) indicaram que a maior limitação, e mais problemática, é o ataque da broca do mogno (Hypsipyla grandella Zeller). $\mathrm{O}$ ataque provoca a necrose do meristema do ápice caulinar e a perda da dominância apical, levando à redução em altura e sucessivas ramificações, tornando a madeira pouco ou não comercializável (PEREZ et al., 2010).

Inseticidas foram formulados com o objetivo de controlar a infestação de $H$. grandella, alguns com resultados promissores, contudo estão relacionados a fortes impactos ambientais e, ou, possuem baixa eficiência no controle (GOULET et al., 2005). Controles alternativos de manejo como o plantio consorciado com eucalipto (Eucalyptus spp.) podem reduzir a taxa de infestação, mas sofrem com a competição interespecífica, reduzindo a altura e o diâmetro do caule do mogno (GUIMARÃES NETO et al., 2004). Estudos evidenciaram que o consórcio com plantas de nim
(Azadirachta indica A. Juss) também pode reduzir os danos da broca, entretanto somente quando o mogno é manejado em baixa densidade de plantio (SILVA et al., 2013). Perez et al. (2010) não constataram redução no ataque da broca quando garfos de mogno-brasileiro foram enxertados em plantas resistentes de mognoafricano (Khaya senegalensis) e toona (Toona ciliata). O pouco sucesso dessas diversas alternativas indicam a dificuldade do controle dessa praga-chave.

Pesquisas que evidenciam a relação entre os nutrientes minerais e a incidência de pragas no mognobrasileiro são escassas, assim como em outras espécies arbóreas (LECOMPTE etal., 2010; FORBES; HOSENHEIM, 2011). Na nutrição mineral do mogno, trabalhos anteriores realizadas por Ohashi et al. (2008) e Silva et al. (2009) indicaram a influência do cálcio e do boro na resistência ao ataque de $H$. grandella, por mecanismos ainda não elucidados. Firmino et al. (2006) verificaram a influência do cálcio e do boro na indução de resistência em plantas de Solanum gilo devido ao aumento da lignificação promovido pelos nutrientes. Almeida et al. (2008), ao estudarem o efeito do silicato de cálcio, verificaram que esse adubo reduziu a população de trips (Thrips palmi) e os danos econômicos provocados pela sua predação em plantas de Solanum melongena.

O cálcio $(\mathrm{Ca})$ atua na síntese da parede celular, como mensageiro secundário em resposta a sinais bióticos e abióticos e é requerido como cofator por enzimas que participam da hidrólise de ATP (TAIZ; ZEIGER, 2009). É encontrado, principalmente, na parede celular apoplástica, compondo os pectatos de cálcio da lamela média (EPSTEIN; BLOOM, 2006), participando da biossíntese de lignina e propiciando resistência a herbívoros em plantas (FIRMINO et al., 2006).

O boro (B) possui funções relacionadas, principalmente, à arquitetura da parede celular (EPSTEIN; BLOOM, 2006), sendo encontrado até 90\% de sua quantidade total armazenada nessa estrutura (MALAVOLTA, 2006). Está ainda envolvido no processo de alongamento celular (TAIZ; ZEIGER, 2009), regulando enzimas, participando do funcionamento

Revista Árvore, Viçosa-MG, v.38, n.6, p.1085-1094, 2014 
das membranas e da síntese de lignina e relacionado também com a resistência a pragas e doenças (MALAVOLTA, 2006).

Diante desse contexto, objetivou-se avaliar o efeito de doses do elemento cálcio e do boro no crescimento da planta, na taxa de infestação e no comprimento da galeria provocada pela $H$. grandella em plantas jovens de mogno cultivadas em solução nutritiva.

\section{MATERIAL E MÉTODOS}

O experimento foi conduzido em casa de vegetação da Área de Ciência do Solo, na Universidade Federal Rural da Amazônia (UFRA), Belém, PA, no período de janeiro a dezembro de 2011. A temperatura média da casa de vegetação variou entre 28 e $37^{\circ} \mathrm{C}$ e a umidade relativa do ar, em torno de $70 \%$ a $90 \%$.

O delineamento experimental utilizado foi o de blocos ao acaso, arranjo fatorial $4 \times 4$, com quatro doses de $\mathrm{Ca}\left(0,100,200\right.$ e $\left.400 \mathrm{mg} \mathrm{L}^{-1}\right)$ e quatro doses de boro $\left(0 ; 0,5 ; 2\right.$ e $\left.4 \mathrm{mgL}^{-1}\right)$ com três repetições e três plantas por repetição, totalizando 48 parcelas e 144 unidades experimentais. As doses de cálcio e de boro selecionadas para compor os tratamentos foram baseadas nos teores propostos por Hoagland e Arnon (1950) para esses elementos, tendo como concentração média recomendada $200 \mathrm{mg} \mathrm{L}^{-1}$ de cálcio e $0,5 \mathrm{mg} \mathrm{L}^{-1}$ de boro para crescimento adequado das plantas.

As unidades experimentais consistiram de vasos plásticos de cor azul com capacidade para $5 \mathrm{~L}$ e drenos na base. A reposição e drenagem da solução nutritiva foram feitas, respectivamente, no início da manhã e final da tarde, de forma manual, diariamente. O substrato utilizado foi sílica moída, tipo grossa. A solução nutritivabase utilizada foi de Hoagland e Arnon (1950) modificada por Sarruge (1975), quanto à pressão osmótica, utilizando sais puros para análise, com renovação periódica semanal e adição, a cada três dias, da água perdida por transpiração. A transpiração diminui a concentração de nutrientes com menor cinética de absorção, que é o caso do Ca e B (MALAVOLTA, 2006).

As plantas de mogno foram originadas de sementes de plantas matrizes da Fazenda Tramontina, no Município de Aurora do Pará, PA. As sementes foram germinadas em bandejas de 50 × 50 × $5 \mathrm{~cm}$, tendo como substrato areia branca lavada e esterilizada, sendo as plântulas transplantadas posteriormente para os vasos definitivos.
Durante 177 dias, cultivou-se o mogno em solução nutritiva com todos os nutrientes para permitir o adequado desenvolvimento das mudas. Após esse período, alterou-se o regime de solução completa para água destilada por quatro dias, visando minimizar os efeitos residuais dos nutrientes. Ao término dos quatro dias, aplicaram-se os tratamentos utilizando novamente a solução inicial de Hoagland, entretanto modificada quanto à adequação das doses estudadas.

Três modificações foram realizadas na solução contendo os tratamentos, sendo: 1 - Uso de solução de micronutrientes sem $\mathrm{B}$, fornecendo as doses do elemento separadamente via $\mathrm{H}_{3} \mathrm{BO}_{3} ; 2$ - Uso de $\mathrm{NaNO}_{3}$ e $\mathrm{NH}_{3} \mathrm{NO}_{3}$ para compensar a perda de $\mathrm{N}$ fornecido pelo $\mathrm{Ca}\left(\mathrm{NO}_{3}\right)_{2}$ nas doses abaixo de $200 \mathrm{mg} \mathrm{L}^{-1}$ de cálcio; 3 - Uso de $\mathrm{CaCl}_{2}$ para aumentar a dose de Ca nas doses acima de $200 \mathrm{mg}$ L de solução nutritiva base. Os tratamentos estudados foram aplicados durante 156 dias, inclusive no período de avaliação do ataque da broca.

Aos 297 dias após o início do experimento (10 de novembro de 2011), foi realizada a inoculação dos ovos de H. grandella em todas as plantas (Figura 1). Realizaram-se duas inoculações por planta em um único momento, fixando com alfinete no caule não lignificado uma tela de tecido de $1 \mathrm{~cm}^{2}$ contendo um ovo viável. A inoculação nesta parte da planta é realizada para facilitar a entrada do herbívoro. Os ovos da broca do mogno foram produzidos no Laboratório de Entomologia da Universidade Federal Rural da Amazônia.

A variável para avaliação da infestação foi a presença ou ausência de serragem e seiva endurecida nos pontos de invasão (Figura 1C) produzida pela destruição do lenho, da parede celular e dos vasos condutores (OHASHI et al., 2008; LUNS et al., 2009), juntamente com a presença ou ausência de galeria formada pela $H$. grandella nos vasos condutores. É importante destacar que a presença de galeria se configura como o melhor parâmetro para avaliação da infestação provocado pelo inseto (OHASHI et al., 2002), sendo esse critério adotado no estudo para quantificação da variável.

O período de avaliação da taxa de infestação e comprimento da galeria foi de 40 dias após a inoculação dos ovos, sendo feito, posteriormente, a separação das partes da planta em raízes e parte aérea, as quais foram colocados em estufa de circulação forçada de ar a $65^{\circ} \mathrm{C}$, visando à obtenção do peso constante, 
assim como realizado por Martielo et al. (2009) em mudas de eucalipto. Os parâmetros de crescimento avaliados no experimento foram: a) altura (AL); b) diâmetro de colo (DC); c) massa seca da parte aérea (MSPA); d) massa seca de raízes (MSR); e) relação parte aérea raiz $^{-1}$ (PA/RA); f) taxa de infestação de H. grandella (TI) e; g) comprimento da galeria (CG) construída pela lagarta.

Os dados de TI e CG sofreram transformação angular de arcossen $\sqrt{X / 100}$ para normalização dos resultados e, juntamente com os demais, foram submetidos à análise de variância, comparando as médias a partir do teste de Tukey a 5\%, com o auxílio do software estatístico SAEG 9.1. As variáveis significativas foram submetidas à análise de regressão, ajustando-se as equações de acordo com o maior coeficiente de determinância $\left(\mathrm{R}^{2}\right)$.

\section{RESULTADOS}

\subsection{Crescimento da planta}

Não foi verificada interação estatística entre os fatores cálcio e boro das variáveis de crescimento $(\mathrm{p}>0,05)$, sendo constatado apenas efeito dos fatores isolados. As doses de Ca e B avaliadas não influenciaram ( $p>0,05)$ a AL e o DC das plantas de mogno, entretanto foi verificado efeito das doses para a produção de $\operatorname{MSR}(p<0,05)$ e MSPA $(\mathrm{p}<0,01)$. Essas variáveis apresentaram comportamento diferenciado em resposta ao aumento das doses dos nutrientes. Para o Ca, o comportamento foi linear (Figura 2AB) e para o B, quadrático (Figura 2CD).

Em geral, as maiores produções de MSR e MSPA foram obtidas no tratamento com supressão do Ca e B nas soluções nutritivas (Tabela 1), sendo elevado os coeficientes de determinação encontrados para essas variáveis, a excessão da MSPA em função das doses de B (Figura 1). Houve variação significativa $(p<0,01)$ na relação PA/RA em resposta ao aumento dos níveis de $\mathrm{Ca}$ e B isoladamente, entretanto a equação que melhor se ajustou aos nutrientes foi a de terceiro grau.

\subsection{Taxa de infestação e comprimento da galeria construída pela broca do mogno}

Não houve interação significativa entre os nutrientes cálcio e boro $(p>0,05)$ para a TI e CG produzidos pela broca, sendo verificado apenas efeito dos fatores isolados (Tabela 1). O ajuste de equação que obteve o melhor coeficiente de determinação para o cálcio versus taxa de infestação foi o quadrático (Figura 2E). O comprimento da galeria em função do cálcio e do boro não se ajustaram a equações de primeiro e segundo graus, apenas de terceiro grau.

A supressão de Ca na solução nutritiva favoreceu o aumento da TI da broca (Figura 1), no entanto, na dosagem de $100 \mathrm{mg} \mathrm{Ca} \mathrm{L}^{-1}$, verificou-se o menor valor de variável (Tabela 1), sendo o efeito das doses acima destas iguais estatisticamente. Houve redução de 41,7\%
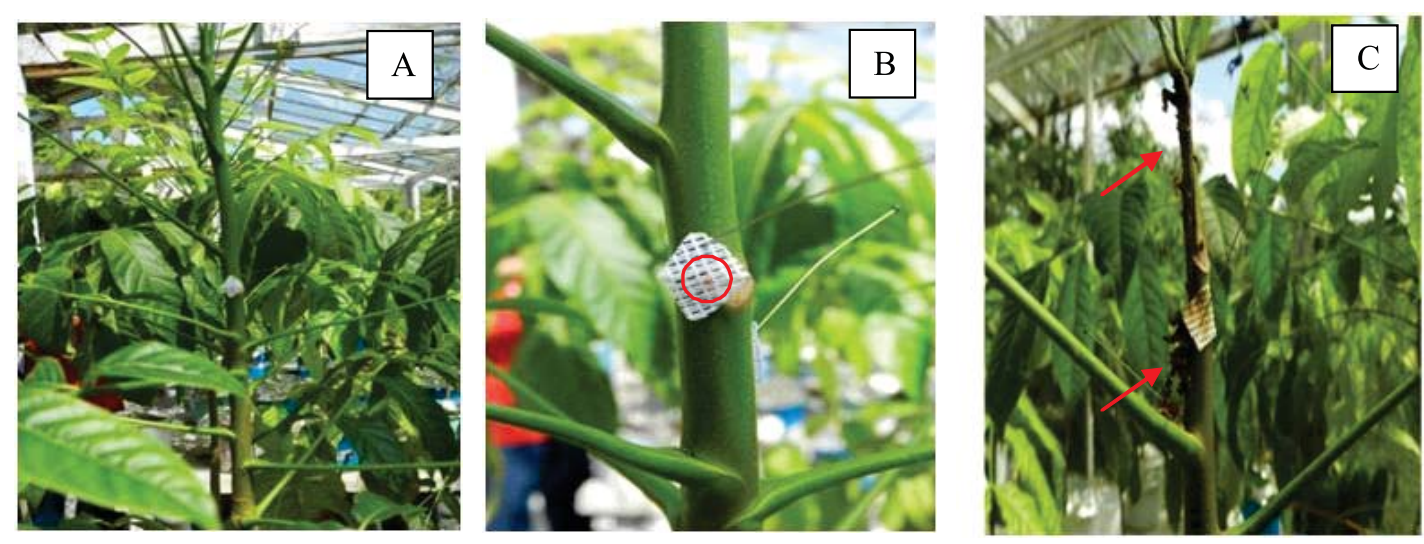

Figura 1 - Plantas de mogno inoculadas com ovos de H. grandella. A: Local de fixação do tecido com ovo de H. grandella na parte superior não lignificada do caule; B: No detalhe, o ovo viável de H. grandella; C: Sintomas de ataque da broca em plantas jovens de mogno, evidenciando a produção de serragem e a destruição do meristema apical.

Figure 1 - Mahogany plants inoculated with eggs of $\boldsymbol{H}$. grandella. A: Place of tissue fixation with egg of $\boldsymbol{H}$. grandella at the top of the not lignified stem, B: In detail, the viable egg of $\boldsymbol{H}$. grandella; and C: Symptoms of shoot-borer attack in seedlings of Mahogany, showing the production of sawdust and the destruction of the apical meristem.

Revista Árvore, Viçosa-MG, v.38, n.6, p.1085-1094, 2014

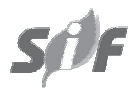




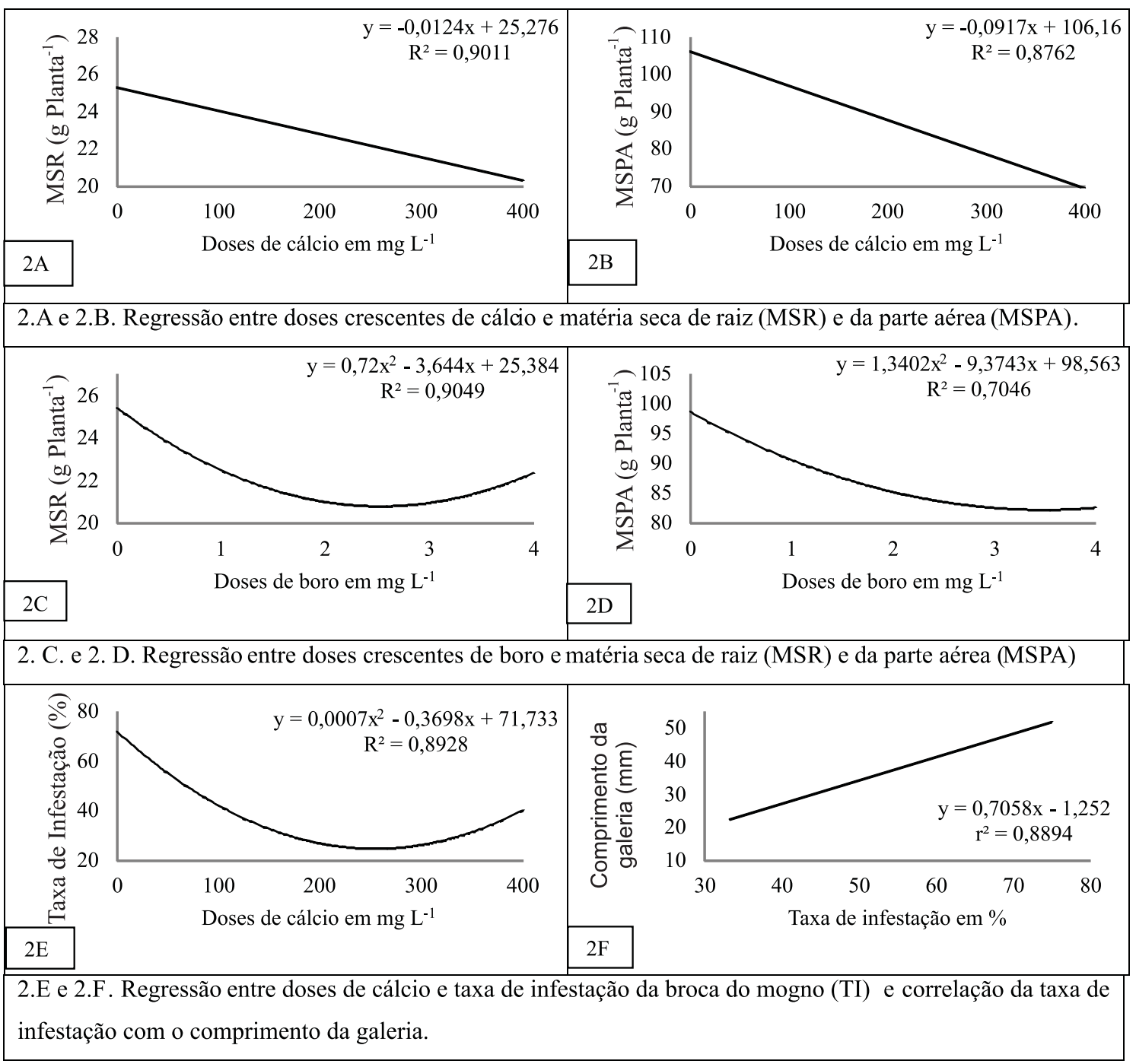

Figura 2 - Ajuste de equações para as variáveis massa seca de raiz (MSR), massa seca da parte aérea (MSPA), taxa de infestação de H. grandella (TI) e correlação entre a taxa de infestação e o comprimento da galeria (TI x CG), em função dos fatores cálcio e boro isolados.

Figure 2 - Adjustments to equations of the variables for root dry mass (MSR), air dry mass (MSPA), infection rate (Infestation rate) and correlation between infestation rate and length of the gallery (Infestation rate $x$ Gallery length) due to calcium and boron isolated factors.

da TI em resposta ao aumento de 0 para $100 \mathrm{mgCa} \mathrm{L}^{-1}$.

O comprimento da galeria construída pela broca de H. grandella foi influenciada pelo cálcio $(\mathrm{p}<0,01)$ e pelo boro $(\mathrm{p}<0,05)$. Houve redução de $38,62 \mathrm{~mm}$ do CG em resposta ao aumento do nível de Ca de 0 para $100 \mathrm{mg} \mathrm{L}^{-1}$, sendo este o nível que proporcionou o menor valor da variável. Em relação ao boro, verificou-se que houve redução dessa variável em $9,5 \mathrm{~mm}$, como resposta ao aumento de 0 para $0,5 \mathrm{mg} \mathrm{L}^{-1}$ de boro e incremento do CG com o aumento das doses desse elemento.

A correlação linear entre taxa de infestação versus comprimento da galeria foi significativa e apresentou elevado coeficiente de determinância (Figura 2F). Não houve significância na correlação entre MSPA versus taxa de infestação $\left(\mathrm{r}^{2}=0,6684\right)$ e MSPA versus comprimento da galeria $\left(r^{2}=0,2521\right)$.

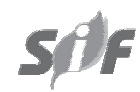

Revista Árvore, Viçosa-MG, v.38, n.6, p.1085-1094, 2014 
Tabela 1 - Médias dos fatores Ca e B isolados para as variáveis altura (AL), diâmetro de colo (DC), massa seca de raiz (MSR), massa seca da parte aérea (MSPA), relação parte aérea/raiz (PA/RA), taxa de infestação (TI) e comprimento da galeria $(\mathrm{CG})^{1}$.

Table 1 - Means of factors Ca and B isolated for the variables height (AL), stem diameter (DC), dry root weight (MSR), aerial part weight (MSPA), ratio aerial/root part (PA/PR), infestation rate (TI) and length of the gallery $(C G)^{1}$.

\begin{tabular}{|c|c|c|c|c|c|c|c|}
\hline \multirow[t]{2}{*}{$\mathrm{mg} \mathrm{L}^{-1}$} & $\mathrm{AL}$ & $\mathrm{DC}$ & CG & MSR & MSPA & $\mathrm{PA} / \mathrm{RA}$ & T I \\
\hline & $\mathrm{cm}$ & \multicolumn{2}{|c|}{$\left(\mathrm{mm} \mathrm{planta} \mathrm{p}^{-1}\right)$} & \multicolumn{2}{|c|}{$\left(\right.$ g planta $\left.^{-1}\right)$} & -- & $\%$ \\
\hline \multicolumn{8}{|c|}{ Doses de cálcio } \\
\hline 0 & $65,07^{\mathrm{ns}}$ & $12,97^{\mathrm{ns}}$ & $51,52 \mathrm{a}^{* * *}$ & $25,99 \mathrm{a}^{*}$ & $106,34 \mathrm{a}^{* * *}$ & $4,14 a b^{* *}$ & $74,99 \mathrm{a}^{* *}$ \\
\hline 100 & $65,31^{\mathrm{ns}}$ & $12,90^{\mathrm{ns}}$ & $12,90 b^{* *}$ & $23,08 \mathrm{ab}^{*}$ & $102,25 b^{* * *}$ & $4,49 a^{* *}$ & $33,33 b^{* *}$ \\
\hline 200 & $65,09^{\mathrm{ns}}$ & $12,53^{\mathrm{ns}}$ & $30,63 \mathrm{ab}^{* *}$ & $22,80 \mathrm{ab}^{*}$ & $79,56 \mathrm{c}^{* *}$ & $3,53 \mathrm{c}^{* * *}$ & $33,33 b^{* *}$ \\
\hline 400 & $64,63^{\mathrm{ns}}$ & $12,64^{\mathrm{ns}}$ & $27,36 b^{* * *}$ & $20,55 b^{*}$ & $72,30 \mathrm{~d}^{* *}$ & $3,54 \mathrm{bc}^{* *}$ & $38,88 b^{* *}$ \\
\hline \multicolumn{8}{|c|}{ Doses de boro } \\
\hline 0 & $64,65^{\mathrm{ns}}$ & $12,66^{\mathrm{ns}}$ & $26,22 \mathrm{ab}^{*}$ & $25,93 \mathrm{a}^{*}$ & $94,22 b^{* *}$ & $3,69 b^{* *}$ & $44,44^{\mathrm{ns}}$ \\
\hline 0,5 & $66,11^{\mathrm{ns}}$ & $12,21^{\mathrm{ns}}$ & $17,70 b^{*}$ & $22,91 \mathrm{ab}^{*}$ & $100,83 \mathrm{a}^{* * *}$ & $4,45 a^{* *}$ & $36,10^{\mathrm{ns}}$ \\
\hline 2 & $63,90^{\mathrm{ns}}$ & $13,13^{\mathrm{ns}}$ & $41,13 a^{*}$ & $21,34 b^{*}$ & $82,28 \mathrm{c}^{* *}$ & $3,92 \mathrm{ab}^{* *}$ & $44,44^{\mathrm{ns}}$ \\
\hline 4 & $60,45^{\mathrm{ns}}$ & $13,04^{\mathrm{ns}}$ & $37,36 \mathrm{ab}^{*}$ & $22,25 \mathrm{ab}^{*}$ & $83,13 c^{* *}$ & $3,73 b^{* * *}$ & $55,55^{\mathrm{ns}}$ \\
\hline dms & 4,48 & 1,43 & 23,41 & 4,06 & 3,65 & 0,58 & 26,59 \\
\hline CV (\%) & 6,22 & 10,11 & 49,45 & 15,85 & 3,66 & 13,31 & 42,18 \\
\hline
\end{tabular}

${ }^{1}$ Letras diferentes para a mesma variável nas colunas mostram variação significativa pelo teste a 5\%; is Interação significativa; * Variação em nível de 5\%; ** Variação em nível de $1 \%$; ns Não significativo; dms diferença mínima significativa e; CV = coeficiente de variação. Fonte: Elaboração dosautores.

${ }^{1}$ Different letters for the same variable in columns show significant variation by test at 5\%; * Range at 5\%; ** Range at the $1 \%$; $n$ s not significant; dms least significant difference; and $C V=$ coefficient of variation.

\section{DISCUSSÃO}

\subsection{Influência do cálcio e do boro na massa seca da parte aérea e das raízes}

As plantas submetidas às omissões de Ca e B apresentaram sintomas de deficiência nutricionais característicos dos nutrientes como clorose, encarquilhamento e posterior necrose de folhas novas e do meristema apical. Quando necrosado o meristema apical, houve ramificação do ápice caulinar, gerando brotos novos, que também foram necrosados.

As plantas expostas às dosagens máximas de cálcio e de boro não tiveram seu meristema apical necrosado, entretanto apresentaram os sintomas de toxidez como clorose e necrose de folhas velhas, decorrentes do possível acúmulo desses elementos nessas regiões de maior atividade metabólica (MALAVOLTA, 2006).

Diferentemente do que propõe Vitti et al. (2006) e Dechen e Nachtigall (2007), os aumentos dos teores de cálcio e boro na solução nutritiva levaram à redução do desenvolvimento radicular para o mogno. Isso está relacionado com a baixa necessidade desses elementos pela planta, fato que pode ter gerado fitotoxidez nas dosagens mais altas, reduzindo o desenvolvimento

Revista Árvore, Viçosa-MG, v.38, n.6, p.1085-1094, 2014 radicular e da parte aérea. Miwa e Fujiwara (2010) mostraram que níveis de B podem facilmente se tornar tóxico às células das plantas. Em contrapartida, altos teores de $\mathrm{Ca}$ e $\mathrm{B}$ podem diminuir o desenvolvimento radicular pela abundância desses minerais na solução e a não necessidade de expansão radicular para aumento de superfície de contato em busca do elemento.

A não significância dos resultados de diâmetro do colo e a altura em função de doses de Ca e B corroboram os resultados encontrados por Souza et al. (2010), que não verificaram resposta em nenhum dos parâmetros de crescimento analisados em plantas de mogno em função da calagem e adubação boratada. Silva et al. (2007) também não encontraram resposta na altura quando mudas de mogno foram submetidas à calagem, mas concordaram com os resultados ao encontrarem significância nas doses para a massa seca da parte aérea, massa seca de raiz e relação parte aérea:raiz.

Os resultados deste estudo indicaram que o cálcio e o boro influenciaram a produção de matéria seca de raiz e da parte aérea, ocorrendo redução dessas variáveis com o aumento das doses desses nutrientes, devido à baixa necessidade nutricional por esses elementos e seu possível efeito fitotóxico quando fornecido em elevada quantidade. Nomura et al. (2011), ao avaliarem

Revista Arvore, Viçosa-MG, v.38, n.6, p.1085-1094, 2014 
o efeito da adubação de boro em plantas adultas de banana, verificaram que esse mineral também não influenciou significativamente a altura e diâmetro do pseudocaule. Gonçalvez et al. (2008) mostraram que mudas de angico-vermelho também não responderam à aplicação de Ca em relação às variáveis de crescimento, pois esse elemento se mostrou um dos menos limitantes para essa espécie.

Clones de eucalipto também apresentaram modelos quadráticos de respostas quando submetidos a doses de boro nos níveis de $0,10,20,50$ e $100 \mu \mathrm{mol} \mathrm{L}^{-1}$ (MARTIELLO al., 2009), que mostraram respostas negativas quando em elevados teores na solução nutritiva, apresentando máximos valores de matéria seca nas mais baixas concentrações, concordando com os resultados deste estudo. Esses resultados também concordaram com os de Gomes da Silva et al. (2007), quando estudaram o efeito da adubação com micronutrientes em mudas de mogno-brasileiro, indicando que a omissão de B também apresentou tendência de maiores resultados em relação à produção de matéria seca.

Zhou et al. (2012), ao avaliarem o crescimento de teca (Tectona grandis) exposta ao Ca e B, verificaram efeito significativo apenas quando esses nutrientes agiram em interação, o que não foi verificado neste estudo. Sena et al. (2010), ao estudarem os efeitos da calagem sobre o crescimento de mudas de angelimpedra, mostraram que doses de cálcio influenciaram na altura, diâmetro do colo, matéria seca da parte aérea e matéria seca da raiz, com exceção da relação parte aérea:raiz. Tucci et al. (2010), de forma contrária à deste estudo, indicaram que a calagem afetou significativamente o crescimento em altura e diâmetro do colo das mudas de pau-de-balsa.

\subsection{Influência do cálcio e do boro na taxa de infestação e no comprimento da galeria construída pela $H$. grandella}

$\mathrm{O}$ ataque da broca nas plantas de mogno ocorreu de forma agressiva, destruindo severamente o meristema apical em no máximo quatro dias após a inoculação. Isso provocou também a ramificação do broto terminal, quebrando a dominância apical das plantas atacadas (Figura 1). Isso ratifica que o principal dano ocasionado pela $H$. grandella é a ramificação do meristema apical, que limita sua comercialização por reduzir a qualidade física da madeira (OHASHI et al., 2002).
Os sinais característicos de infestação visual (Figura 1C) como a serragem e seiva nos pontos de invasão se manifestaram em $75 \%$ do total do número de plantas, entretanto, desse total, 70\% não possuíam galeria formada nos vasos condutores. Isso mostra que a classificação como infestadas ou não unicamente pela presença da seiva e, ou, serragem nos pontos de invasão não é confiável, pois superestima a taxa de infestação devido ao fato de a maioria das plantas atacadas não apresentar evolução no ataque e, consequentemente, não desencadearia danos significativos à madeira.

Em estudos anteriores, Silva et al. (2009) encontraram resultados que convergem com os deste estudo, quando avaliaram a resistência de plantas de mogno ao ataque da broca submetidas a doses de Ca. Esses autores verificaram que o aumento das doses de Ca reduziu a taxa de infestação para $20 \%$ na dosagem de $320 \mathrm{mg}$ $\mathrm{Ca} \mathrm{L}^{1}$, além de também afetar o comprimento da galeria. Ohashi et al. (2002) também verificaram efeitos de redução na taxa de infestação da broca do mogno em resposta à aplicação de calcário.

A resistência induzida pelo Ca pode ser explicada pela relação de vários mecanismos fisiológicos e bioquímicos de defesa da planta ativados por esse nutriente, entretanto dois fatores se destacam. O primeiro está relacionado ao fato de que o fornecimento de $\mathrm{Ca}$, em teores ideais, pode estimular mecanismos de defesa da planta, sintetizando mais lignina e pectatos de cálcio (FIRMINO et al., 2006). A lignina possui rigidez física que proporciona menor consumo pelos herbívoros e, por ser estável quimicamente, é pouco digestível. Além disso, o processo de lignificação pode induzir bloqueios ao crescimento de patógenos (TAIZ; ZEIGER, 2009).

Firmino et al. (2006), ao estudarem a relação entre Ca e B no processo de lignificação em plantas de Solanum gilo, visando à maior resistência a patógenos, concluíram que maiores teores de $\mathrm{Ca}$ e $\mathrm{B}$ promovem maior comprimento e espessura do vaso condutor e das fibras. No caso do mogno-brasileiro, teores adequados desses elementos podem ter proporcionado maior rigidez e, consequentemente, maior resistência à penetração física da lagarta no caule. Esse efeito pode ter promovido redução e, ou, estagnação na movimentação da broca nos vasos condutores, dificultando ou impossibilitando a formação da galeria. A deficiência de cálcio afetou, ainda, o meristema apical do mogno, levando à flacidez 
e, ou, necrose dos tecidos meristemáticos (VITTI et al., 2006), fato que provavelmente aumentou a suscetibilidade ao ataque da lagarta, apesar de a supressão de Ca aumentar a MSPA e MSR.

O B em teores elevados pode ter-se tornado fitotóxico ao mogno, indicado a partir da queda na produção de biomassa e no aumento do comprimento da galeria com o aumento das doses do elemento. A citotoxidade do boro pode afetar o movimento de cálcio do citoplasma para a parede celular (FIRMINO et al., 2006), fato que pode reduzir a síntese de lignina.

O cálcio em altas concentrações também pode ter-se tornado citotóxico, afetando o seu próprio movimento do citoplasma para a parede celular, já que níveis tóxicos de Ca levam à redução na produção de energia devido a precipitação de fosfato inorgânico, podendo este último alterar as funções das membranas (MALAVOLTA, 2006) e limitar o bombeamento de Ca pelas Ca-ATPase do vacúolo para a parede celular (ISHIDA; VOGEL, 2010). Esse efeito pode ter minimizado o potencial de lignificação e de defesa da planta.

O segundo mecanismo que pode estar relacionado ao potencial de defesa promovido pelo fornecimento de Ca é que a deficiência do elemento pode aumentar o tempo de reação da planta ao ataque de pragas (ARIMURA; MAFFEI, 2010). Epstein e Bloom (2006) mostraram que, quase sem exceção, o estresse que as plantas sofrem promove aumento na concentração de $\mathrm{Ca}^{+2}$ no citoplasma e, sob a eliminação do estresse, a concentração de Ca volta ao normal. Esse desbalanço é detectado pela planta que desencadeia uma resposta bioquímica, principalmente relacionada com fitohormônios (etileno), espécies reativas de oxigênio, óxidos nitrosos, ácido salicílico e outros compostos químicos (ARIMURA; MAFFEI, 2010). Isso permite que a planta ative eficientemente seus mecanismos de defesa em tempo hábil, reduzindo, assim, os danos ocasionados pelas pragas.

A partir da detecção desse estímulo por parte da planta, é desencadeada a síntese de calmodulinas, compostos que atuam na regulagem de proteínas e de fito-hormônios, que ativam grupos de enzimas que induzem uma resposta por parte da planta, como a produção de metabólitos secundários, aumento da biossíntese de lignina e outras estratégias de defesas (PEROCHON et al., 2011).

\section{CONCLUSÃO}

1. O cálcio e o boro são nutrientes fundamentais no controle da broca do mogno.

2. O mogno é pouco tolerante a elevados níveis de cálcio e boro.

3. Estudos que relacionam o cálcio e o boro com o ataque de Hypsipyla grandella precisam ser ampliados para melhorar a eficiência no controle da broca do mogno.

\section{AGRADECIMENTOS}

Ao The International Tropical Timber Organization - ITTO, pelo fomento financeiro ao Projeto Management of Hypsipyla grandella in Swietenia macrophylla King plantations in Pará and São Paulo States, Brazil, que custeou esta pesquisa.

\section{REFERÊNCIAS}

ALMEIDA, G. D.; PRATISSOLI, D.; ZANUNCIO, J. C.; VICENTINI, V. B.; HOLTZ, A. M; SERRÃO, J. E. Calcium silicate and organic mineral fertilizer applications reduce phytophagy by Thrips palmi karny (Thysanoptera- T hripidae) on eggplants (Solanum melongena L.). Interciência, v.33, n. 11, p. 835-838, 2008.

ARIMURA, G. I.; MAFFEI, M. E. Calcium and secondary CPK signaling in plants in response to herbivore attack. Biochemical and

Biophysical Research

Communications, v.400, n.4, p.455-460, 2010.

CARVAlHO, P. E. R. Mogno - Swietenia macrophylla. Colombo: Embrapa, 2007. 12 p. (Circular Técnica, 140)

DECHEN, A. R.; NACHTIGALL, G. R. Elementos requeridos à nutrição de plantas. In: NOVAIS, R. F. et al. Fertilidade do solo. Viçosa, MG: Sociedade Brasileira de Ciência do Solo, 2007. v.1. $1017 \mathrm{p}$.

DEGEN, B.; WARD, S. E.; LEMES, M. R.; NAVARRO, C.; CAVERS, S.; SEBBEN, A. M. Verifying the geographic origin of mahogany (Swietenia macrophylla King) with DNAfingerprints. Forensic Science

International: Genetics, v.7, n.1, p.55-62, 2013. 
EPSTEIN, E.; BLOOM, A. Nutrição mineral de plantas. Londrina: Planta, 2006. v.1. 416 p.

FIRMINO, A.; ABREU, H. S.; PORTUGAL, A. C. P.; NASCIMENTO, A. M.; SOUZA, E. L.; PEREIRA, R. P. W.; MONTEIRO, M. B. O.; MAÊDA, J. M. Alterações ligno-anatômicas em Solanum gilo Raddi por aplicação de cálcio e boro como estratégia de defesa. Ciência Agrotécnica, v.30, n.3, p.394-401, 2006.

FORBES, A. A.; ROSENHEIM, J. A. Plant responses to insect herbivore damage are modulated by phosphorus nutrition.

Entomologia Experimentalis et Applicata, v.139, n.3, p.242-249, 2011.

GONÇALVEZ, E. O.; PAIVA, H. N.; NEVES, J. C. L.; GOMES, J. M. Crescimento de mudas de angico-vermelho (Anadenanthera marocarpa (Benth.) Brenan) sob diferentes doses de macronutrientes. Revista Árvore, v.32, n.6, p.1029-1040, 2008.

GOULET, E.; RUEDA, A.; SHELTON, A.

Management of the mahogany shoot borer, Hypsipyla grandella (Zeller)

(Lepidoptera:Pyralidae), through weed management and insecticidal sprays in 1- and 2year-old Swietenia humilis Zucc. plantations. Crop Protection, v.24, p.821-828, 2005.

GROGAN, J.; BARRETO, P.; VERÍSSIMO, A. Mogno na Amazônia brasileira: ecologia e perspectivas de manejo. Belem: Imazon, 2002. 56 p.

GUIMARÃES NETO, A. B.; FELFILI, J. M.; SILVA, G. F.; MAZZEI, L.; FAGG, C. W.; NOGUEIRA, P. E. Avaliação do plantio homogêneo de mogno, Swietenia macrophylla King, em comporação com o plantio consorciado com Eucalyptus urophylla S. T. Blake, após 40 meses de idade. Revista Árvore, v.28, n.6, p.777-784, 2004.

HOAGLAND, D. R.; ARNON, D. I. The water culture method of growing plants without soil. Berkeley: Agricultural Experimental Station, 1950. 347p.

ISHIDA, H.; VOGEL, H. J. The solution structure of a plant calmodulin and the CaM-binding domain of the vacuolar calcium-ATPase BCA1 reveals a new binding and activation mechanism. The Journal of Biological Chemistry, v.285, n.49, p.38502-38510, 2010.

LECOMPTE, F.; ABRO, M. A.; NICOT, P. C. Contrasted responses of Botrytis cinerea isolates developing on tomato plants grown under different nitrogen nutrition regimes. Plant Pathology, v.19, n.5, p.891-899, 2010.

LUNZ, A. M.; THORNAZINI, M. J.; MORAES, M. C. B.; NEVES, E. J. M.; BATISTA, T. F. C.; DEGENHARDT, J; SOUSA, L. A.; OHASHI, O. S. Hypsipyla grandella em Mogno (Swietenia macrophylla): Situação Atual e Perspectivas. Pesquisa Florestal Brasileira, n.59, p.45$55,2009$.

MALAVolta, E. Manual de nutrição mineral de plantas. São Paulo: Agronômica Ceres, 2006. 638 p.

MARTIELLO, E. M.; RUIZ, H. A.; SILVA, I. R.; GUERRA, P. C.; ANDRADE, V. M. Características fisiológicas e crescimento de clones de eucalipto em resposta ao boro. Revista Árvore, v.33, n.5, p.821-830, 2009.

MIWA, K.; FUJIWARA, T. Boron transport in plants: co-ordinated regulation of transporters. Annals of Botany, v.105, p.1103-1108, 2010.

NOMURA, E. S.; TEIXEIRA, L. A. J.; BOARETTO, R. M.; GARCIA, V. A.; FUZITANI, E. J.; JUNIOR, E. R. D.; SAES, L. A.; JUNIOR, D. M. Aplicação de boro em bananeira. Revista Brasileira de Fruticultura, v. 33, n.2, p.608-617, 2011.

NORGHAUER, J. M.; MALCOLM, J. R.; ZIMMERMAN, B. L.; FELFILI, J. M. Experimental establishment of big-leaf mahogany (Swietenia macrophylla King) seedlings on two soil types in native forest of Pará, Brazil. Forest Ecology and Management, v.255, n.2, p.282-291, 2008.

OHASHI, O. S.; SILVA JUNIOR, M. L.; LAMEIRA, O. A.; SILVA, J. N. M.; LEÃO, N. V. M.; TEREZO, E. F.; BATISTA, T. F. C.; HIDAKA, D. Z. L.; ALMEIDA, G. B.; BITTENCOURT, P. R. G.; GOMES, F. S.; NEVES, G. S. M. Danos e controle da broca de Hypsipyla grandella em plantio de mogno Swietenia macrophylla no Estado do Pará.

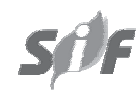

Revista Árvore, Viçosa-MG, v.38, n.6, p.1085-1094, 2014 
In: POLTRONIERE, L. S.; TRINDADE, D. R.; SANTOS, I. P. Pragas e doenças de cultivos amazônicos. 2.ed. Manaus: Embrapa Amazônia Oriental, 2008. 379 p.

OHASHI, O. S. et al. Manejo Integrado da broca do mogno Hypsipyla grandella Zeller (Lep. Pyralidae). In: POLTRENIERI, L. S.; TRINDADE, $D$. R. Manejo integrado das principais pragas e doenças de cultivos amazônicos. Manaus: Embrapa Amazônia Oriental, 2002. 304p.

PEREZ, J.; EIGENBRODE, S. D.; HILJE, L.; TRIPEPI, R. R.; AGUILAR, M. E.; MESEN, F. Use of grafting to prevent Hypsipyla grandella (Zeller) (Lepidoptera: Pyralidae) damage to new world meliaceae species. Neotropical Entomology, v.39, n.4, p.618-625, 2010.

PEROCHON, A.; ALDON, D., GALAUD, J. P.; RANTY, B. Calmodulin and calmodulin-like proteins in plant calcium signaling. Biochimie, v.93, n.2, p.2048-2053, 2011.

SARRUGE, J. R. Soluções nutritivas. Summa Phytopathologica, v.1, n.3, p.231-233, 1975.

SENA, J. S. S.; TUCCI, C. A. F.; LIMA, H. N.; HARA, F. A. S. Efeito da calagem e da correção dos teores de $\mathrm{Ca}$ e $\mathrm{Mg}$ do solo sobre o crescimento de mudas de angelim-pedra (Dinizia excelsa Ducke). Acta Amazonica, v.40, n.2, p.309-318, 2010.

SILVA, A. R. M; TUCCI, C. A. F.; LIMA, H. N.; FIGUEIREDO, A. F. Doses crescentes de corretivos na formação de mudas de mogno (Swietenia macrophylla King). Acta

Amazonica, v.37, n.2, p.195-200, 2007.

SILVA, M. C. A; ROSA, L. S.; VIEIRA, T. A. Eficiência do nim (Azadirachta indica A. Juss) como barreira natural ao ataque de Hypsipyla grandella (Zeller (Lepidoptera: Pyralidae) sobre o mogno (Swietenia macrophylla King). Acta Amazonica, v.43, n.1, p.19-24, 2013.

SILVA, S. A. S.; SANTOS, M. M. L. S.; SILVA, G. R. S.; SILVA JUNIOR, M. L.; OHASHI, O. S.;
RUIVO, M. L. P. Efeito do cálcio no controle da Hypsipyla grandella em mudas de mogno cultivadas em hidroponia. Acta Amazonica, v.39, n.2, p.273-278, 2009.

SILVA, W. G; TUCCI, C. A. F.; HARA, F. A. S.; SANTOS, R. A. C. Efeito de micronutrientes sobre o crescimento de mudas de mogno (Swietenia macrophilla King) em Latossolo Amarelo. Acta Amazonica, v.37, n.3, p.371-376, 2007.

SOUZA, C. A. S.; TUCCI, C. A. F.; SILVA, J. F; RIBEIRO, W. O. Exigências nutricionais e crescimento de plantas de mogno (Swietenia macrophylla King). Acta Amazonica, v.40, n.3, p.515-522, 2010.

TAIZ, L.; ZEIGER, E. Fisiologia vegetal. 4.ed. Porto Alegre: Artmed, 2009. 848 p.

TUCCI, C. A. F.; LIMA, H. N.; GAMA, A. S.; COSTA, H. S.; SOUZA, P. A. Efeitos de doses crescentes de calcário em solo Latossolo Amarelo na produção de mudas de pau-de-balsa (Ochroma lagopus sw., bombacaceae). Acta Amazonica, v.40, n.3, p.543-548, 2010.

VIEIRA, T. A. Sistemas agroflorestais em áreas de agricultores familiares em Igarapé-Açu, Pará: caracterização florística, implantação e manejo. Acta Amazonica, v.37, n.4, p.549-558, 2007.

VITTI, G. C.; LIMA, E.; CICARONE, F. Cálcio, magnésio e enxofre. In: FERNANDES, M. S. F. Nutrição mineral de plantas. Viçosa, MG: Sociedade Brasileira de Ciência do Solo, 2006. v.1. 432p.

WALLAU, R. L. R.; BORGES, A. R.; ALMEIDA, D. R.; CAMARGOS, S. L. Sintomas de deficiências nutricionas em mudas de mogno cultivadas em solução nutriva. Cerne, v.14, n.4,p.304-310, 2008.

ZHOU, Z.; LIANG, K.; XU, D.; ZHANG, Y.; HUANG, G.; MA, HUAMING. Effects of calcium, boron and nitrogen fertilization on the growth of teak (Tectona grandis) seedlings and chemical property of acidic soil substrate. New Forrest, v.43, n.2, p.231-243, 2012. 